\title{
COATLICHAN. LÍNEAS Y COLORES EN EL ACOLHUACAN. \\ UN ACERCAMIENTO A LA TOPONIMIA Y LA COMPLEJIDAD ETNICA*
}

\author{
Luz María Mohar Betancourt. \\ Centro de Investigaciones y Estudios Superiores en Antropología Social. \\ México D.F. México.
}

El objetivo de este trabajo es mostrar un panorama de la importancia de la documentación pictográfica, de los documentos existentes en relación al señorío de Coatlichan, para ejemplificar con el tema de la toponimia los asentamientos de diversos grupos étnicos en un mismo territorio.

$\mathrm{El}$ interés por las antiguas culturas Mesoamericanas cuenta con una fuente inagotable de información con el estudio de la documentación pictográfica elaborada por los antiguos habitantes de esta zona de alta cultura.

Aunados a los restos arqueológicos testimonio del desarrollo y el refinamiento logrado por sus habitantes, la documentación pictográfica hace patente la importancia de la comunicación y el desarrollo cultural logrado en esta región. Al igual que en el Viejo Mundo, en el México antiguo se desarrollaron complejos sistemas de escritura evidentes en el arte de hacer libros. Estos libros pintados fueron descritos por el cronista real Pedro Mártir de Anglería primer europeo radicado en el viejo mundo de la siguiente manera:

"vengamos ya a los regalos que se enviaron al rey, empezando por los libros... ya hemos dicho que estas gentes los poselan... por dondequiera que

* El presente trabajo es parte de un otro más amplio titulado El Mapa de Coatlichan. Lineas y colores en el Acolbuacan. 
el libro se abra aparecen dos caras escritas,... los caracteres que se usan son muy diferentes a los vuestros consisten de dados, ganchos, lazos, limas y otros objetos dispuestos en línea como entre nosotros y casi semejantes a la escritura egipcia"...continua diciendo "sus libros cuando están cerrados se parecen a los nuestros y contienen según se cree sus leyes, el orden de sus sacrificios y ceremonias, sus cuentas anotaciones astronómicas y los modos y tiempos de sembrar." 1 .

Es interesante sefialar como en ese momento este hombre entendió la importancia de estos documentos, así como la riqueza de información contenidos en ellos.

Si bien la variedad de temas contenidos en estos libros, ahora sabemos que es mayor a lo considerado por Anglería, es interesante señalar como los equipara con los libros europeos, haciendo notar su diferencia.

Pintados sobre diferentes materiales como el amate o papel de corteza de árbol, lienzos de algodón o pieles de animales, estos documentos elaborados en el México antiguo sufrieron su destrucción tanto por el hombre como por la naturaleza.

En este segundo punto desafortunadamente por el tipo de materiales sobre los que se elaboraron su deterioro en ocasiones los destruyó totalmente ante la embestida de insectos, roedores, humedades o incendios.

En el caso de los códices prehispánicos muchos de ellos fueron destruidos en las guerras de conquista entre los diferentes grupos del México antiguo, especialmente por los propios mexicas como símbolo de sometimiento, al incendiar templos y palacios de las poblaciones vencidas.

Posteriormente, como resultado de la conquista española, fueron los propios conquistadores y los religiosos, especialmente los frailes, quienes tomaron como tarea la destrucción de estos manuscritos por su relación con la religión, especialmente con los ritos y las fiestas. Sin saber distinguir entre la variedad de temáticas que se plasmaban en los documentos, estos fueron destrozados sin hacer distinción alguna, baste recordar los "autos de fe " realizados por los obispos Fray Juan de Zumárraga en Tetzcoco y Fray Diego de Landa en Maní, quienes durante varios días mantuvieron una hoguera en la que se consumían los códices que habían encontrado.

Habría que recordar también a personajes como Olmos, Mendieta, Sahagún y Durán así como numerosos laicos que supieron aquilatar su valor y la riqueza de su contenido, gracias a quienes se lograron conservar importantes códices que son fuentes primordiales actualmente ${ }^{2}$.

Los mismos cronistas hacen posible saber que existía una producción muy grande de esta documentación, en la que se anotaban tanto los hechos 
históricos como las genealogías, los registros de tierras, las ceremonias y los ritos, así como la descripción geográfica de los diferentes lugares, además de los registros tributarios. Los amoxcalli eran los palacios en los que se guardaban innumerables documentos indígenas. Baste recordar aquí las palabras de Bernal Díaz del Castillo quien dice:

“... eran en aquel tiempo su mayordomo mayor un gran cacique, que le pusimos por nombre Tapia y tenía cuenta de todas las rentas que le traían a Moctezuma con sus libros, hechos de su papel, que se dice amal, y tenía de estos libros una gran casa de ellos". ${ }^{3}$

\section{LOS TLACUILOS.}

Los tlacuilos o pintores de códices eran verdaderos especialistas ligados tanto a la administración como al sacerdocio y en general a la nobleza. Gracias a ellos se anotaban con gran maestría los eventos y acontecimientos por medio de elementos gráficos. Un rasgo característico de este sistema de escritura era delinear los elementos en negro para posteriormente colorearlos a la aguada.

La amplia gama de colores utilizados por los tlacuilos es una muestra del manejo hábil de tintes y colorantes obtenidos tanto de plantas como animales o de origen mineral ${ }^{4}$.

La variedad de testimonios pictográficos con los que se cuenta actualmente a permitido a diversos investigadores hablar de diferentes escuelas de pintura en el México antiguo.

Si bien se desconoce el momento en el que esta tradición se inició en el Nuevo Mundo es cierto que comparten los registros existentes rasgos mesoamericanos que los hacen comunes pero que a su vez distinguen a las diferentes escuelas tanto del centro de México como de Mesoamérica en general.

En el caso del centro de México se distinguen principalmente la escuela de Tezcoco, la Mexica de Tenochtitlan y la Tlatelolca's además de los Códices Mixtecos y del Area Maya.

\section{LA TRADICIÓN PICTOGRÁFICA}

La tradición de escribir pintando se mantuvo muchos años después de la llegada de los españoles al Nuevo Mundo. En muchos casos inclusive la 
producción de material de carácter jurídico aumentó considerablemente. Por medio de este sistema los indios peleaban sus tierras, su legitimidad como herederos, su genealogía, mostraban su historia, sus conquistas y batallas, así como su organización social y política ${ }^{6}$.

La influencia que sobre ellos ejerció el nuevo orden se distingue en este tipo de documentación por la presencia de nuevos elementos en la pintura indígena, así como el claro obscuro y el sombreado, entre otros. Muchos de los antiguos tlacuilos aprendieron nuevas técnicas y supieron combinar su tradición con las nuevas formas.

\section{CLASIFICACIÓN DE LAS PICTOGRAFIAS}

Como resultado de la aparición de nuevos elementos, los códices se han clasificado actualmente de manera general en prehispánicos y coloniales ${ }^{7}$. Si bien esta clasificación puede resultar inadecuada dado que en la producción colonial gran parte del contenido se refiere a la época prehispánica, sin embargo en muchos de los documentos la aparición de glosas en caracteres latinos ya sea en lenguas indígenas o en castellano, los ubican en este conjunto.

La aparición de papel europeo como el soporte sobre el cual los tlacuilos deslizaban su pincel, así como el formato de los nevos códices a manera de libros europeos, abandonando las formas tradicionales de tiras, son algunos de los elementos que dan fundamento a esta división.

La temática desarrollada en los documentos ha servido también para hacer otro tipo de divisiones. Jhon Glass publicó una clasificación de la Colección del Museo Nacional de Antropología a la que llamó tipológica. Los rubros que él consideró fueron:

Códices de tipo ritual-calendárico, de tipo histórico, de tipo genealógico, de tipo cartográfico, cartográfico histórico, económico, de tipo Techialoyan, de tipo Testeriano, del tipo de los libros de Chilam Balam y finalmente los Códices no clasificados. Además incluyó una clasificación regional partiendo de los diferentes estados de la actual República Mexicana ${ }^{8}$.

\section{LOS MAPAS}

Bajo esta división se han incorporado un buen número de documentos especialmente coloniales. Si bien estos materiales cuentan de manera importante con elementos tales como montañas, ríos, lagos, caminos, vege- 
tación, etc. incluyen además una gran variedad de elementos que generalmente no se encuentran en los mapas europeos. Por ello, puede decirse que son simultáneamente históricos, genealógicos, tributarios, o catastrales.

Es posible pensar que el mismo gobernante mexica, Moctezuma contase con estos tipos de registros en los que se anotaban las diferentes regiones que habían caído bajo su poderío y los diferentes recursos de la naturaleza que las rodeaban así como sus limites y extensiones.

En este sentido el cronista Bernal Díaz del Castillo escribe:

“...volvamos a decir cómo le dio el gran Moctezuma a nuestro capitán en un paño de henequén pintados y señalados muy al natural todos los ríos y ancones que había en la costa del Norte desde Pánuco hasta Tabasco, que son obra de ciento cuarenta leguas, y en ello venía señalado el Río Guazacaqualco, e como ya sablamos todos los puertos e ancones que señalaban en el paño que le dio Montezuma, de cuando venimos a descubrir con Grijalva, aceto el río de Guzaqualco, que dijeron que era muy poderoso e hondo..."

En relación a los mapas del México antiguo el Doctor Joaquín Galarza ha hecho notar como estos documentos están orientados, ya que basados en la observación del sol, el eje principal es Oriente - Poniente, por lo tanto en la mayoría de los mapas de esta tradición, el oriente se encuentra en la parte superior del documento ${ }^{10}$.

\section{EL MAPA DE COATLICHAN}

El mapa de Coatlichan está pintado sobre una sola hoja de papel de corteza que mide $44.5 \times 41.5$ centímetros. A diferencia de otros documentos pintados sobre este tipo de material los cuales tienen "imprimatura", es decir una preparación blanquecina que empareja la superficie sobre la cual pinta el tlacuilo, en este caso se pintó directamente sobre el papel amate, el cual está finamente elaborado. Su color a diferencia de otros documentos en los que el tono del papel es café, en este caso, prácticamente el color es amarillo muy claro lo que en ocasiones lo confunde con papel europeo.

El Mapa recibe su nombre de la lectura en náhuatl del glifo "que se pintó en la parte central de documento. Está formado por una cabeza de serpiente coath que sale de una casa calli o ichan morada, que está pintada sobre un cerro o tepetl cuya base se encuentra rodeada de agua, atl cuya lectura sería cobuatlichan altepetl es decir, el pueblo de la morada o casa de la serpiente. De este glifo central se desprenden una serie de seis líneas de diferente color, cada una enlaza a un conjunto de topónimos o nombres de lugar pintados según la tradición indígena. 


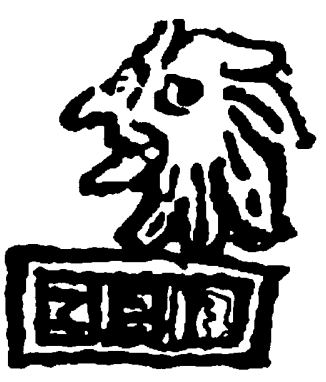

\section{EL MAPA DE COATLICHAN}

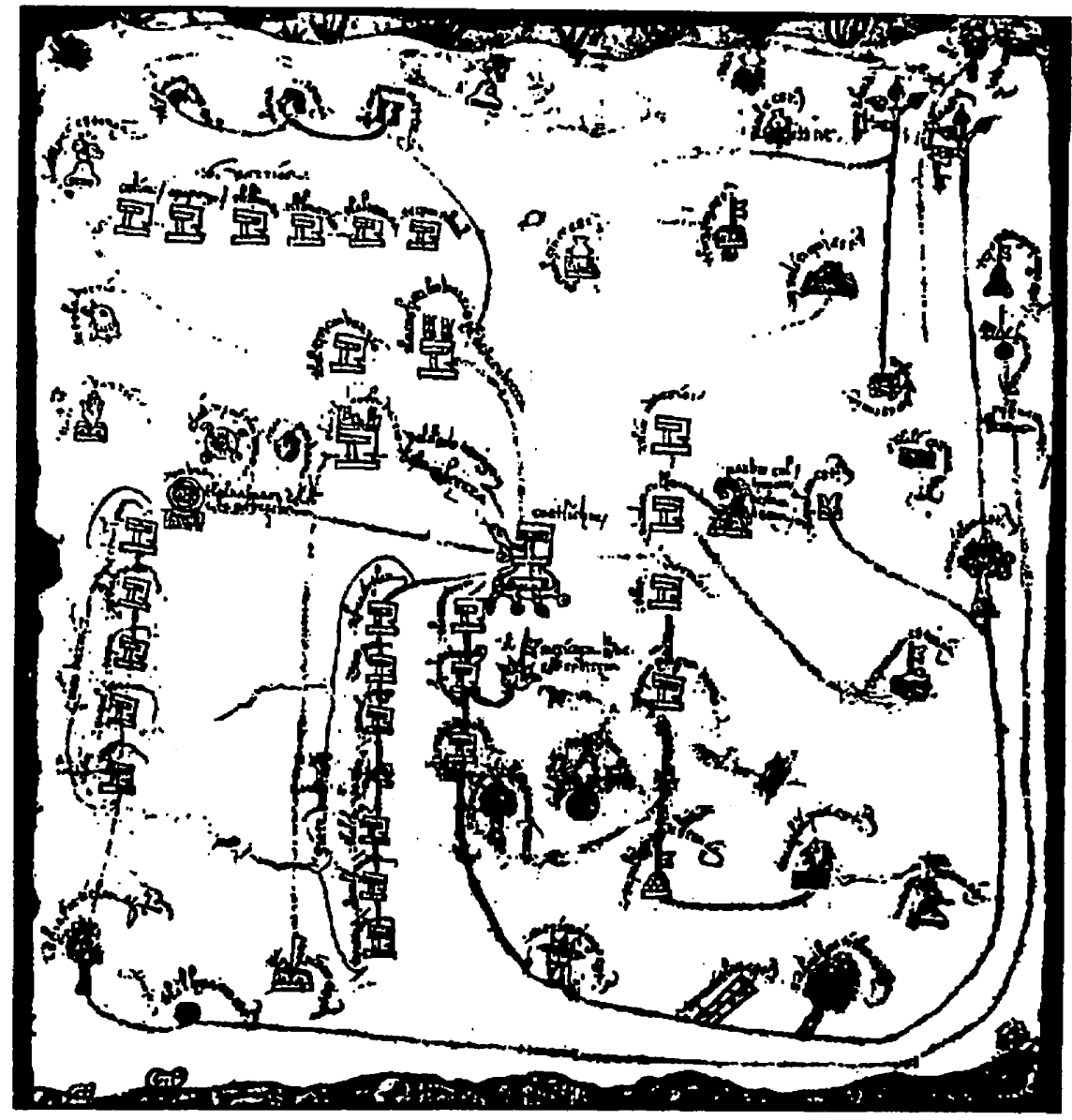

Mapa de Coatlichan, edicion de 1977. 


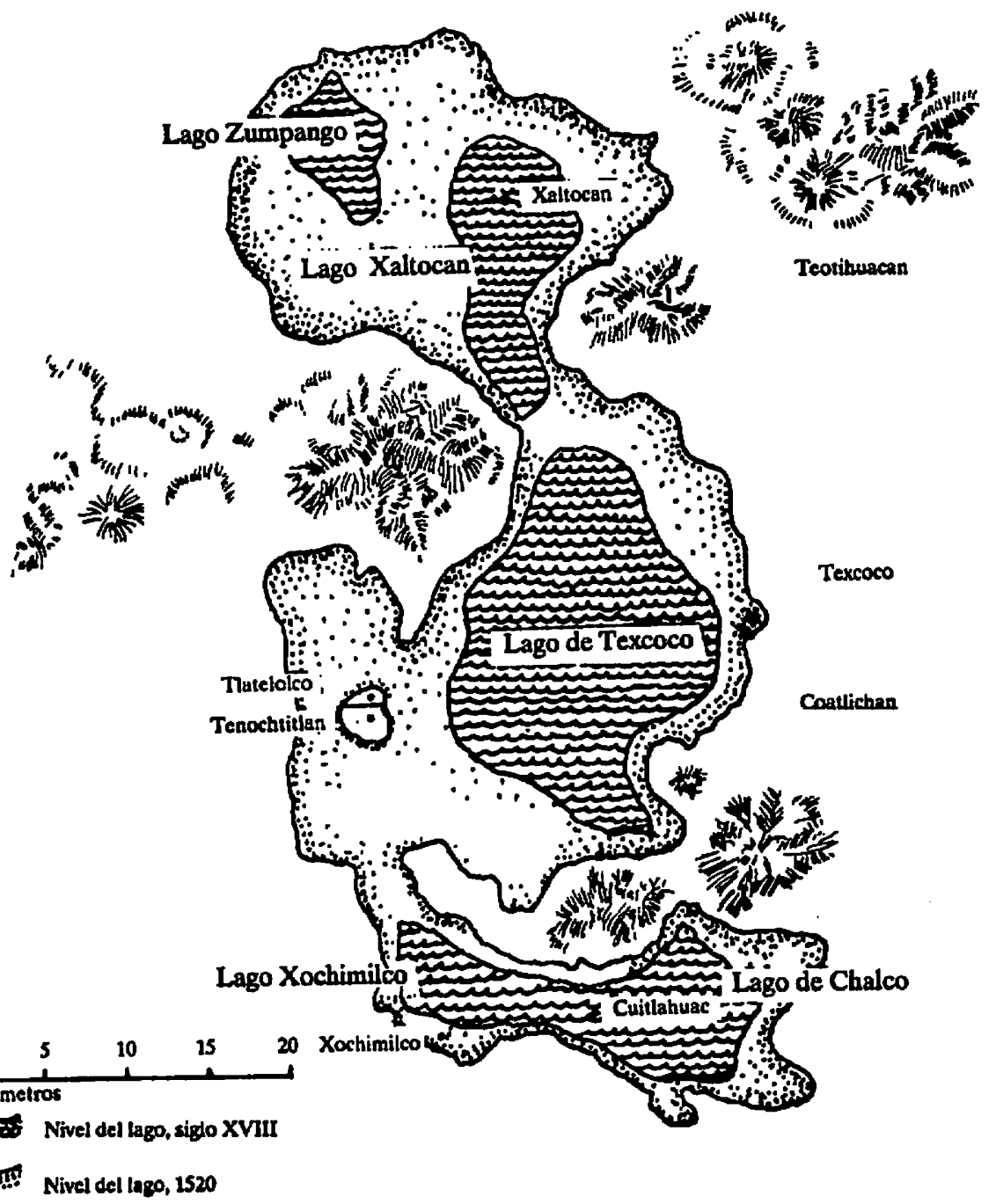

Mapa 1.-Localidades de Coatlichan en la cuenca de México.

Dado que el mapa tiene una serie de anotaciones en caracteres latinos, así como por la introducción de ciertos elementos europeos en el diseño de algunos de sus dibujos se le ha clasificado como un documento colonial del siglo XVI ${ }^{12}$.

Coatlichan fue un importante señorío que floreció en el Posclásico tardío fechado entre 1200 y 1521 d.C. en la Cuenca de México en la región conocida como Acolhuacan. 


\section{EL ACOLHUACAN}

Coatlichan fue uno de los señoríos más significativos del espacio geográfico y cultural conocido como el Acolhuacan. Localizado al oriente del Valle de México, esta región constituyó una zona privilegiada debido a la gran variedad de recursos derivados de una ecología que contemplaba tanto el Lago de Tezcoco como abundantes ríos, una variedad de plantas, espaciosos valles y pronunciadas montañas.

Del Acolhuacan se ha dicho que su territorio posee unidad geográfica e histórica. Limita al norte con la parte baja del río Mexquipayac, los cerros de Tezoyuca y las serranías del Tezontlaxtle y Patlachique, que separan al Acolhuacan del Valle de Teotihuacan; al sur, el Valle comprendido entre la sierra de Ocotepec y el cerro de Chimalhuacan, a la orilla del Lago de Tezcoco; al oriente y sureste las estribaciones de las serranías de San Telmo Tlamacas, Tlaloc, Telapan y Ocotepec, y al occidente con el Lago de Tezcoco. El Acolhuacan se dividió en dos grandes secciones, la zona meridional que limita al norte con los ríos Chapingo y Tezcoco, en la cual se desarrollaron los antiguos señoríos de Coatlichan y Huexotla, y la septentrional al norte de la indicada divisoria en donde floreció el viejo señorío de Tetzcoco ${ }^{13}$.

La región fue habitada del siglo XI al XVI por numerosos grupos étnicos en diferentes etapas de desarrollo cultural. En relación a sus pobladores la caída de Tula se menciona como el punto de arranque que dio origen a la ocupación de este espacio.

Tula cuya fundación se remonta al siglo VIII fue un gran centro cultural que combinaría la herencia cultural del mundo clásico mesoamericano con las aportaciones de los nuevos pueblos venidos de fuera del centro de México. A partir de su caída, en el siglo XII ${ }^{14}$ la documentación tanto escrita como pictográfica hace referencia a un movimiento muy intenso de diferentes grupos en el espacio geográfico del centro del territorio Mesoamericano ocupado por lo que sería la Nueva España.

La documentación pictográfica más importante relacionada con la llegada de grupos étnicos a este territorio se encuentra en los llamados códices chichimecas que constituyen según el estudio de Donald Robertson la llamada escuela Texcocana de códices.

El Códice Xolotl ${ }^{15}$ documento formado por 10 láminas de papel amate anota la llegada al centro de México del grupo llamado e identificado como chichimeca. Este grupo a diferencia de aquellos que habitaron Tula, procedía de la parte norte del territorio y se le identificó como un grupo de cazadores recolectores en contraste con los Toltecas que eran grupos de alta cultura. 
Para reconstruir la historia de Coatlichan y su fundación la consulta de este documento se hace indispensable. El Códice indica la llegada al territorio de el lider chichimeca identificado como Xolotl, aproximadamente entre el siglo XI o XII. En la primera de sus láminas se pintaron los recorridos que él y su grupo hicieron por un territorio en el que vivían algunos toltecas distribuidos en el lugar y se pintaron los lugares en los que finalmente se asentaron en convivencia con los toltecas.

Es la lámina dos de este códice la que nos interesa, ya que en ella se representa la llegada de tres personajes ante Xolotl, para solicitarle tierras y sus autorización para establecerse.

Cada uno de estos lideres se pintó con su antropónimo o nombre a la manera indígena tradicional. Las fuentes escritas como son los textos de Fernando de Alva Ixtlilxochitl describen como : " llegaron las naciones acolhuas, tepanecas y otomites...los cuales trajeron tres señores y cabezas con el mismo intento de poblar esta tierra...y dada la obediencia le pidieron tierras en donde ellos y sus vasallos poblasen..y (Xolotl) les hizo muchas mercedes que fue hacerlos sus yernos..." 16 .

Continúa el texto mencionando como a Acolhua quién iba a la cabeza de los tepanecas le dio a una de sus hijas, y lo estableció en Azcapotzalco, al segundo Chiconcuauh señor Otomf le dio para establecerse Xaltocan y al tercero, señor de los acolhuas, llamado Tzontecoma le dio como esposa a una señora Tolteca y el lugar para establecerse fue Coatlichan.

Es interesante mencionar como a partir de ese momento la historia de Tezcoco y de Coatlichan se relatan de manera paralela. Este último señorío se menciona como un centro que logra desarrollar la agricultura, se relaciona por vía de matrimonio con las grandes casas nobles del centro de México y logra consolidar un importante centro de enseñanza que se menciona como el calmecac o escuela para los hijos de la nobleza en el que se educa. Acamapichtli, quien sería uno de los gobernantes mexicas.

El papel que juega el señorío de Coatlichan como aliado de los descendientes de Xolotl, es fundamental para fortalecer a lo que sería después la gran ciudad de Tezcoco. Las alianzas matrimoniales entre los descendientes de estos dos lugares son constantemente mencionadas en las fuentes escritas. En las láminas del Códice Xolotl, cuyo interés central es resaltar la importancia y desarrollo de los señores del Acolhuacan, Coatlinchan ocupa un lugar preponderante.

Otra fuente pictográfica perteneciente a esta misma escuela de pintura de códices lo constituye el Códice Quinatzin. Este documento formado por tres láminas pintadas sobre papel amate, muestra inicialmente el desarrollo 
de los primeros pobladores chichimecas así como la consolidación de los descendientes de Xolotl. Se pintan dos escenas en la que los señores chcichimecas reciben a otros grupos y les conceden su autorización para establecerse en su territorio a cambio de reconocimiento. Esto sucede en el período de gobierno de Quinatzin (1062) y de Techotlalatzin quien muere en 1357.

Ante Quinatzin se dibujó la llegada de Chimalpanecas y Tlailotlacas. Destacan como parte de los atributos de los recién llegados su atuendo mucho más elaborado, que contrasta con el que porta el mismo Quinatzin a quien se le identifica como cazador, ya que sostiene a un lado de su asiento que lo identifica como autoridad, un arco y sus flechas.

En la misma lámina del Códice Quinatzin se dibujó a Techotlalatizn, se hace evidente un cambio en su atuendo, ya que aparece cubierto con una manta, a diferencia de sus antecesores que se pintaron con pieles de animales como su atuendo característico. Frente a él se registró la llegada de los mexitin, los huiznahuaques y los tepanecas, quienes huían de los Tepanecas de Azcapotzalco.

Cabe mencionar que en la representación de estos grupos se señala la importancia de la agricultura y otras actividades propias de los grupos de alta cultura mesoamericana.

En la siguiente escena del Códice se pintó el palacio de Nezahualcoyotl, con este personaje sentado en la parte central, acompañado de su heredero Nezahualpilli. Cabe señalar que la disposición de los diferentes salones que conformaban el palacio, son una muestra de la complejidad a la que habían llegado los descendientes de Xolotl. El consejo del señorío de los Acolhuas se conformaba por 14 señores, los cuales se registraron en la parte central del palacio, cada uno con su nombre. Rodea a esta escena una serie de topónimos diferenciados que marcan la distinción entre aquellos que tributaban al señorío $y$ aquellos que tributaban a Nezahualcoyotl y Nezahualpilli directamente. Entre estos señores y en un sitio cercano al tlahtoani se pintó al gobernante de Coatlichan.

Es interesante considerar como en estas dos pictografías en la que los propios indígenas pintaron su historia, la presencia del señorío de Coaltichan aparece como una constante.

\section{LA COMPOSICIÓN ÉTNICA EN EL ALCOLHUACAN}

Como ya se ha mencionado las informaciones más tempranas sobre el origen de los habitantes del oriente de la Cuenca de México se inician entre el siglo XI y XII ${ }^{17}$ con la llegada de Xolotl, para continuar con el arribo ante 
este lider chichimeca de otros grupos como los tepanecas, otomies y acolhuas.

Coatlinchan se convierte en el asentamiento acolhua y al igual que en el caso de los chichimecas, la llegada de nuevos grupos van conformando la complejidad del señorío.

Las fuentes pictográficas ya mencionadas anotan la llegada de nuevos grupos. Durante el período de gobierno de Huetzin, nieto de Tzontecoma, fundador del señorío, en el año 1300, llegan a asentarse los chimalpanecas y los tlailotlacas ${ }^{18}$. Estos grupos a los que se les ha identificado como procedentes de la mixteca, se les asocia con la pintura de códices, como hombres sabios que enriquecieron la cultura local y por ello son acogidos, en los diversos señoríos del Acolhuacan.

Los relatos tanto de cronistas como de las pictografías del área relatan la llegada de nuevos grupos. A fines del siglo XIV durante el período de gobierno de Coxcox arriban a Coatlichan los culhuas quienes se establecen en cuatro barrios: el de los mexitin, de los colhuaques, de los huiznahuaques y el de los tepanecas. Este modelo se repitió tanto en Tezcoco como en otros señoríos del Acolhuacan.

Las presiones que en este período sufren los gobernantes de Tezcoco por parte de los Tepanecas de Azcapotzalco, desencadena una serie de batallas entre ambos grupos en los que los señores de Coatlichan muestran su apoyo a los Tezcocanos ${ }^{19}$. La derrota final de estos últimos y la preponderancia de los Tepanecas culmina con la reorganización del Acolhuacan. En ese momento Coatlichan adquiere la categoría de centro recolector de tributos y cabecera del tlabtocayotl ${ }^{20}$. La solidaridad que la nobleza de Coatlichan mostró hacia los Tezcocanos fue severamente castigada por el propio Tezozomoc quien deseaba eliminar a Nezahualcoyotl como heredero del señorío.

La muerte de Tezozomoc y consecuentemente el debilitamiento de su señorío heredado por su hijo Maxtla es un pasaje histórico ampliamente documentado,"1 baste mencionar que debido a esta coyuntura Nezahualcoyotl recuperó con el apoyo de tenochcas y tepanecas su propio señorío, y se instaló como máximo gobernante del Acolhuacan en Tezcoco.

En este período Coatlichan pierde su importancia como centro político ante el apoyo de los aliados de Nezahualcoyotl. Una de las primeras actividades de Nezahualcoyotl una vez recuperado el señorío fue reinstalar a la nobleza que había sido desplazada por los tepanecas.

En Coatlichan nombra a Motoliniatzin quien había huido a Tlaxcala. Es precisamente este gobernante quién aparece pintado en el códice Quinatzin, como parte del consejo del gobernante de Tezcoco ${ }^{22}$. 
A partir de este momento Tezcoco, aliado con Tenochtitlan y Tlacopan constituyen la llamada Triple Alianza. Esta alianza les permitió a los tres señoríos dominar gran parte del territorio Mesoamericano, consolidar su hegemonía y extraer de las poblaciones sometidas grandes cantidades de tributo tanto en materias primas como elaboradas, así como en servicio tanto en el apoyo para sus guerras como en la construcción de obras públicas y el cultivo de los campos.

La presencia de Coatlichan como parte importante del Acolhuacan y de su nobleza se mantuvo hasta la llegada de Cortés. Su estrecha relación con la casa Tezcocana hasta los últimos períodos previos a la conquista española, son prueba evidente con el matrimonio de una hija de Nezahualpilli con Xaquintzin, gobernante de Coatlichan en 1519.

En 1522 Hernán Cortés se asignó a sí mismo toda el área de Tezcoco y sus subordinados. Posteriormente varios lugares fueron asignados a otras personas. En 1525 Cortés perdió la encomienda, la recuperó al año siguiente, finalmente pasó a la Corona en $15310^{23}$

Años más tarde alrededor de 1580 este antiguo señorío recibió su categoría de pueblo cabecera independiente de Tezcoco con sus propias autoridades indigenas.

Aunado al documento o Mapa que es el motivo de este trabajo, Coatlichan a legado a la humanidad el monolito conocido como Tlaloc que identifica en la ciudad de México la entrada al Museo Nacional de Antropología. Testimonio de la grandeza de este lugar. Actualmente la población recibe el nombre de Coatlinchan y se encuentra 7.5 kilómetros de la ciudad de Tezcoco, al oriente del Valle de México.

\section{DESCRIPCIÓN DEL MAPA DE COATLICHAN}

El mapa está formado por una sola hoja en la cual el tlacuilo distribuyó alrededor del topónimo principal que le da su nombre, un conjunto de topónimos o nombres de lugar.

Los elementos básicos son los topónimos que ocupan la mayor parte del espacio. En la parte superior estos se encuentran enmarcados por una delimitación geográfica señalada por el pintor mediante una línea negra ondulante sobre la cual aparecen varios rasgos en negro que identifican de manera abstracta a un conjunto de magueyes sobre fondo verde.

En la parte inferior el mapa tiene una línea negra ondulante coloreada en azul turquesa que representa el agua en movimiento pintada a la manera 
como los antiguos mexicanos lo hacían, en cuyo borde se incluyeron dos pequeños caracoles.

Los topónimos siguen la tradición indígena ya que se encuentran delineados en negro y posteriormente coloreados, algunos de ellos carecen de color y toman el del papel.

Como ya se ha mencionado el mapa cuenta con anotaciones o glosas en caracteres latinos. Estas glosas se refieren al nombre de cada uno de los glifos de lugar y señalan una diferenciación entre cabeceras, barrios y estancias.

De esta manera se distinguen las diferentes jurisdicciones de cada uno de los lugares que conformaban el señorío de Coatlichan. Entendemos como cabecera a la capital donde había un gobernante indígena local que llevaba el título detlahtoani.

El termino en sí indica que hay otros lugares como serían los barrios, que dependen de esa cabecera. La palabra estancia se ha usado para identificar a aquellos lugares que dependen de una cabecera pero que se encuentran distantes de la misma, a diferencia de los barrios ${ }^{24}$.

El glifo central o direccional por su tamaño se identifica como el más importante del conjunto, de él se desprenden seis líneas que enlazan y separan a los topónimos formando conjuntos que se distribuyen a todo lo largo de la línea de color por los diferentes espacios del mapa.

Cada una de ellas sale del glifo central en diferentes direcciones, sin embargo nunca se enciman o se cruzan sino que al contrario se extienden en diferentes direcciones de una manera armónica.

Colores como el amarillo ocre, el rojo, rojo claro, verde o azul turquesa fueron usados por el tlacuilo como guías para distribuir a los diferentes elementos en el espacio. Es posible que la línea roja se haya decolorado con el tiempo. En contraste las líneas en azul turquesa son notables por que conservan la intensidad de su color.

Las anotaciones se escribieron en tinta color sepia, la que contrasta con la línea negra que contorna a los diferentes glifos.

En relación al tipo de línea se distinguen básicamente continuas así como dos ejemplos de punteadas. Las líneas de color son un ejemplo de la habilidad del tlacuilo, ya que en ocasiones una misma atraviesa todo el espacio del mapa y no se ve interrumpida en sus diferentes secciones.

Como ha escrito el Doctor Galarza en relación a este tipo de documentos a diferencia de los mapas europeos, estos se encuentran orientados, como es el caso del Mapa de Coatlichan ${ }^{25}$. En este, el norte se localiza a la izquierda del documento, el sur a la derecha y el oriente en la parte superior 
del mismo, consecuentemente el poniente es la parte inferior de la pintura. Señala como "en los mapas tradicionales indígenas el contenido temático cartográfico no es esencial ni básico. El plano cartográfico le sirve para situar en el espacio los demás elementos del mapa, pero no trata de reproducir fielmente por medio de ciertas convenciones la realidad absoluta o total de una región o de un espacio terrestre" ${ }^{26}$.

\section{LOS TOPONIMOS}

En relación a los nombre de lugar destacan notables diferencias que los agrupan básicamente en dos conjuntos. Algunos de ellos como las cabeceras y las estancias se pintaron con los elementos de dibujo indígena que permite hacer una lectura de sus elementos en náhuatl, a diferencia de aquellos que bajo la anotación de barrios, comparten un mismo elemento que es un calli. Este calli usado en la escritura para identificar una casa vista de perfil se usó en todos los casos, por ello, de acuerdo con la pictografía no se puede hacer una lectura distinta a la que anotan los caracteres latinos.

\section{LAS LINEAS DE COLOR}

Al seguir cada una de las trazos de color la variedad de elementos pintados sobre estas líneas guía y las características de cada uno, proporcionan importante información que permiten entender la conformación de este señorío.

En un trabajo previo se hizo una clasificación en la que mediante letras de la $\mathrm{A}$ a la $\mathrm{F}$ se identificaron a cada uno de los elementos pintados sobre ellas se les dio un número a partir del glifo direccional hasta el extremo de la línea.

Seleccionamos a la amarilla ocre como la línea $\mathrm{A}$ y a los topónimos les dimos un número que abarca del $\mathrm{Al}$ al $\mathrm{A} 10$ sin distinguir entre cabeceras, barrios o estancias.

Siguiendo un orden contrario a las manecillas del reloj, a la línea roja la nombramos como B y los topónimos que incluye yan del B1 al B 11. La línea $\mathrm{C}$ de color verde contiene del $\mathrm{C} 1$ al $\mathrm{C} 11$. Enseguida una línea corta únicamente de barrios sobre azul turquesa enumera del D1 al D7. La línea $\mathrm{E}$ del mismo color que la anterior de gran intensidad incluye del E1 al E10. La última línea o $\mathrm{F}$ es muy compleja en su diseño, incluye del $\mathrm{F} 1$ al F12b.

Encontramos que en la mayoría de las líneas el primer topónimo cuenta con la anotación que lo identifica como cabecera, enseguida los topónimos 
COATLICHAN. LINEAS Y COLORES EN EL ACOLHUACAN.

Línea A (ocre)

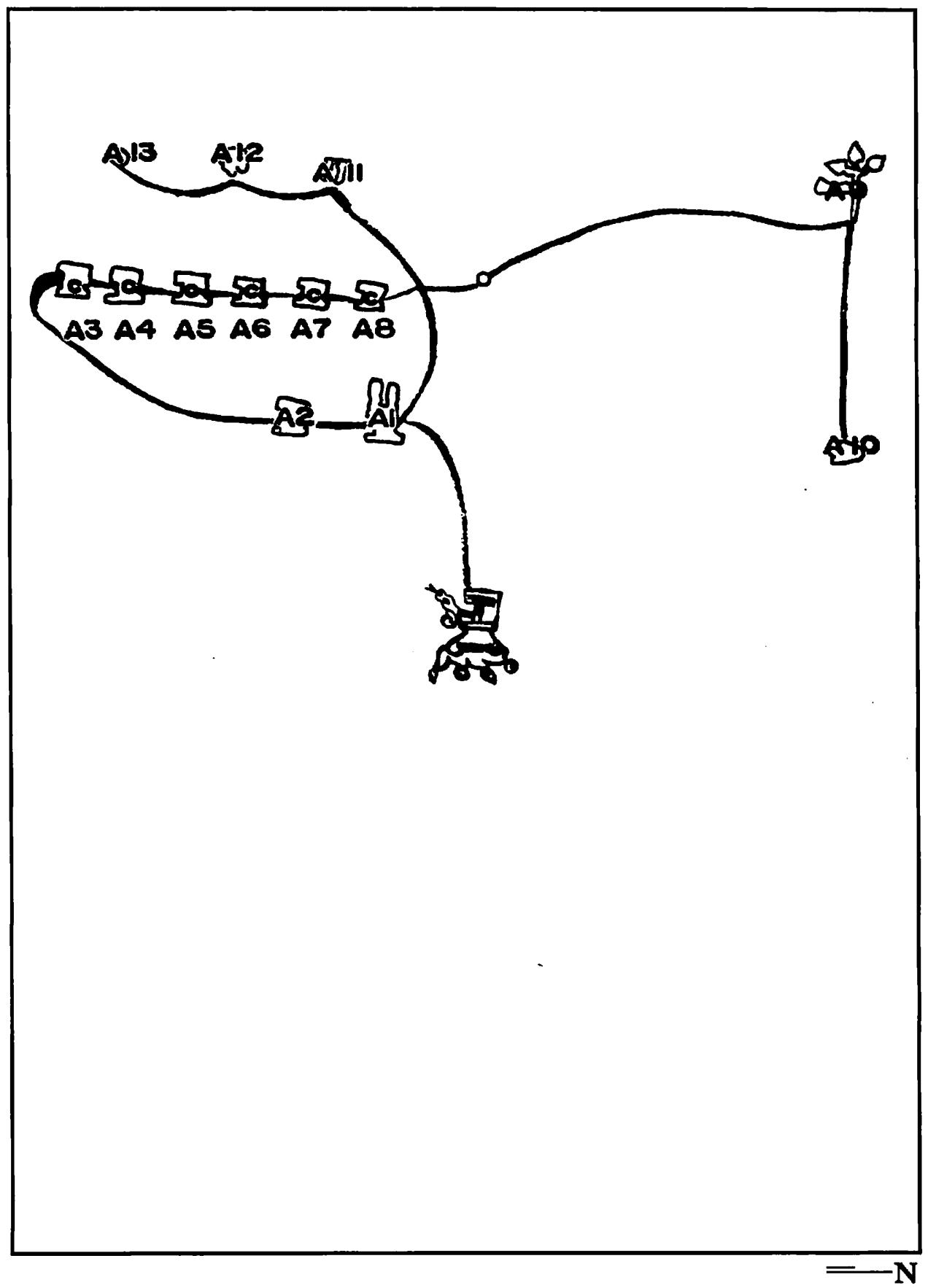




\section{Línea B (rojo)}

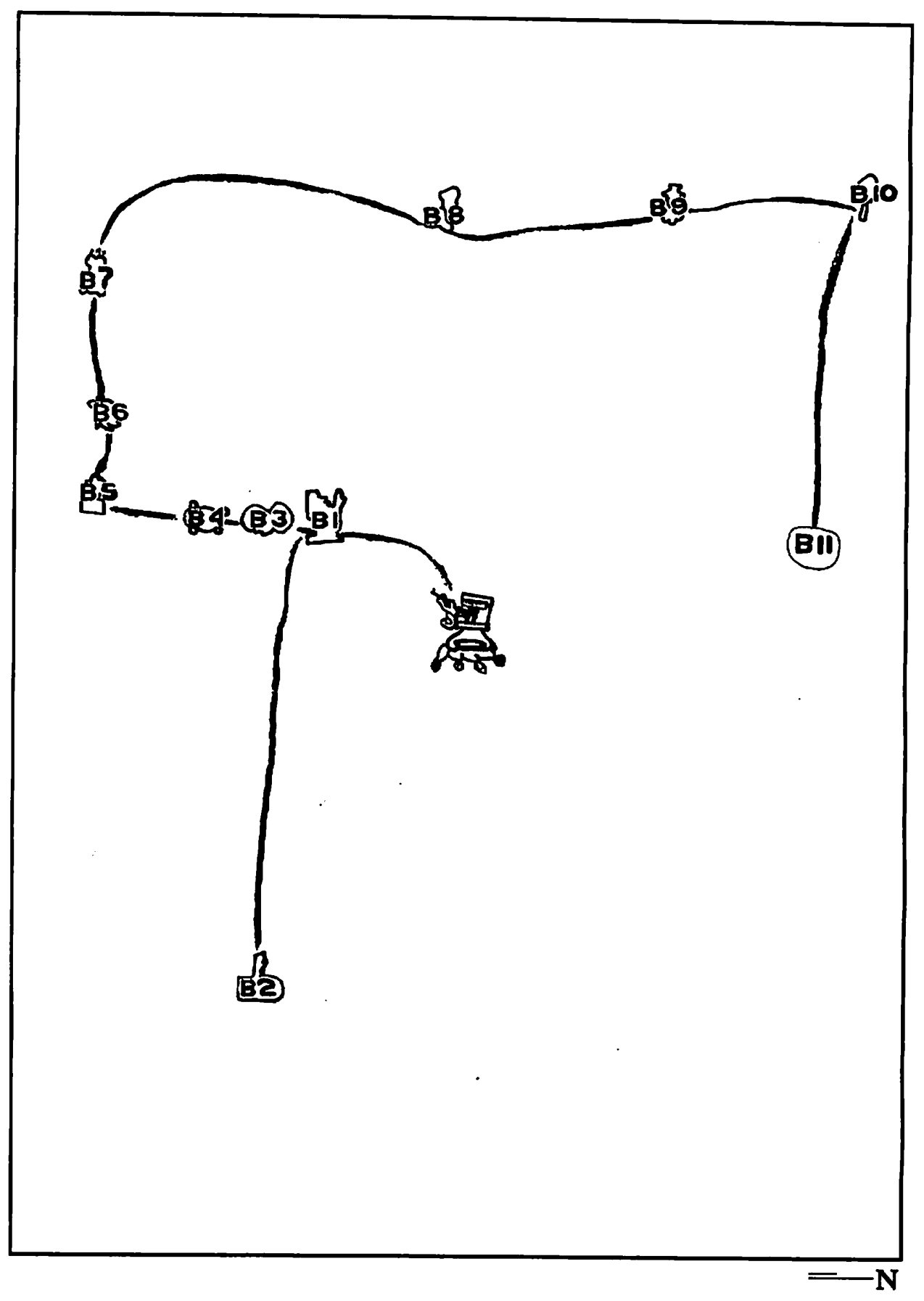


COATLICHAN. LINEAS Y COLORES EN EL ACOLHUACAN,

Línea C (verde)

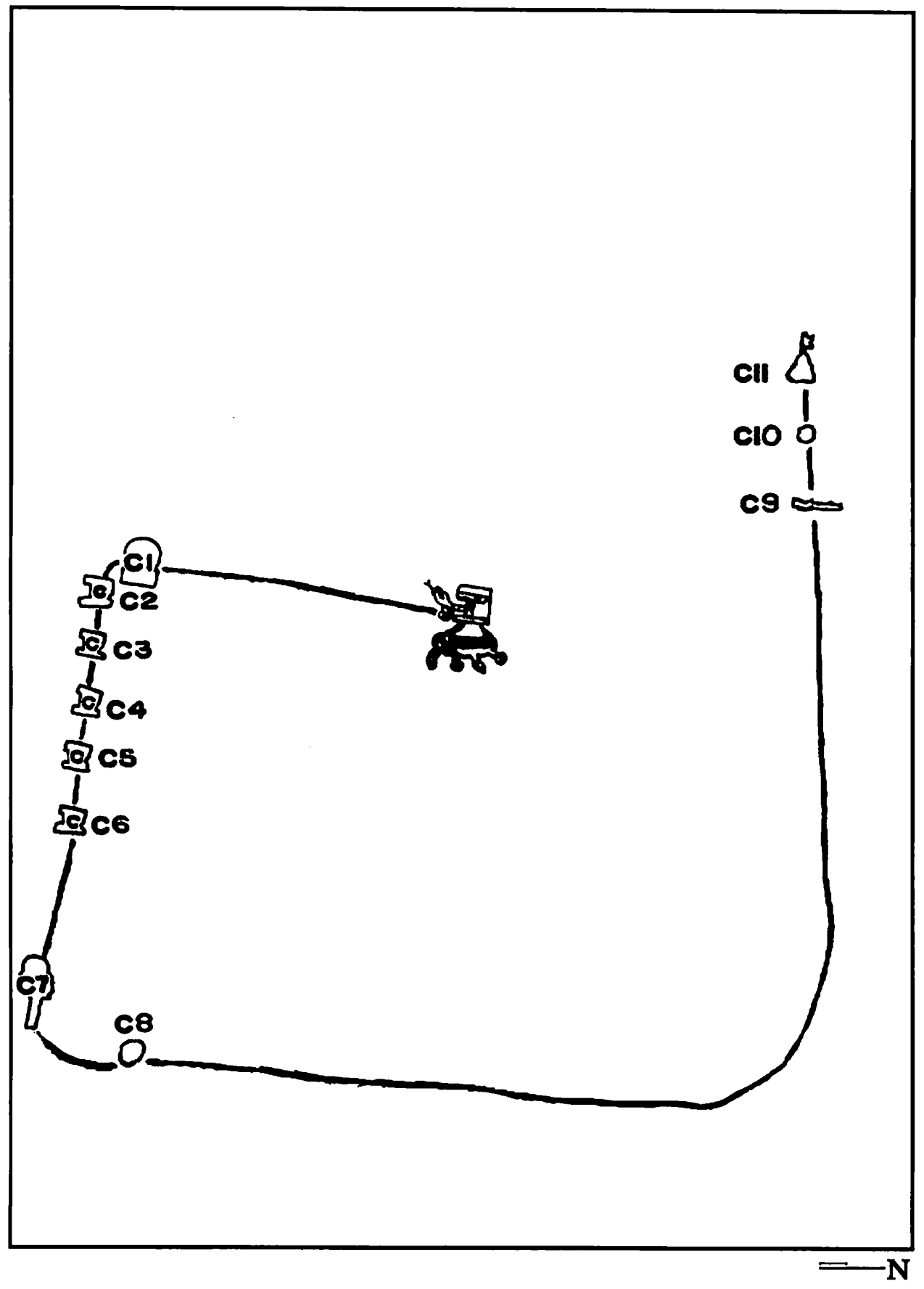




\section{Línea D (azul turquesa)}

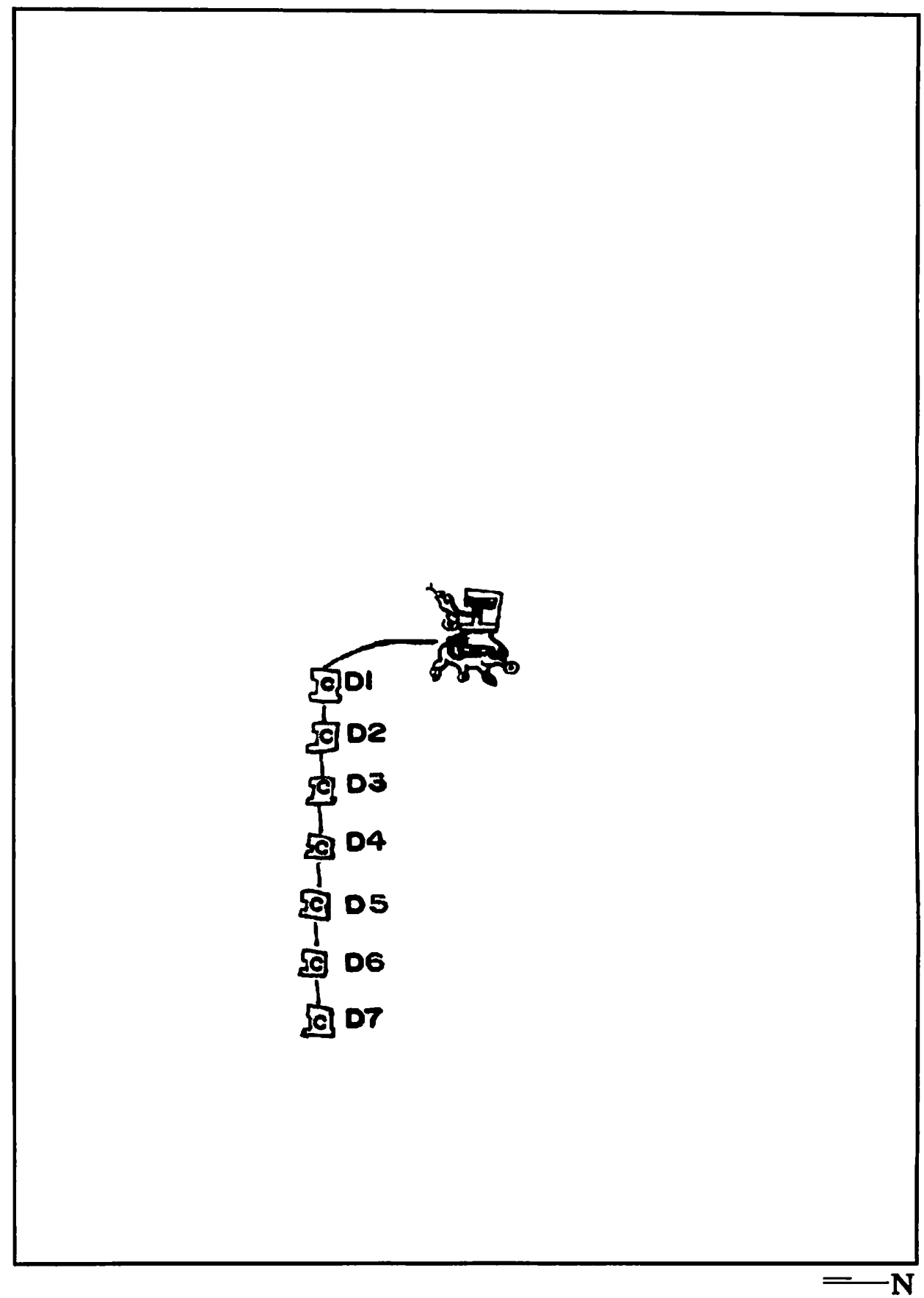


COATLICHAN. LINEAS Y COLORES EN EL ACOLHUACAN.

Línea E (azul turquesa)

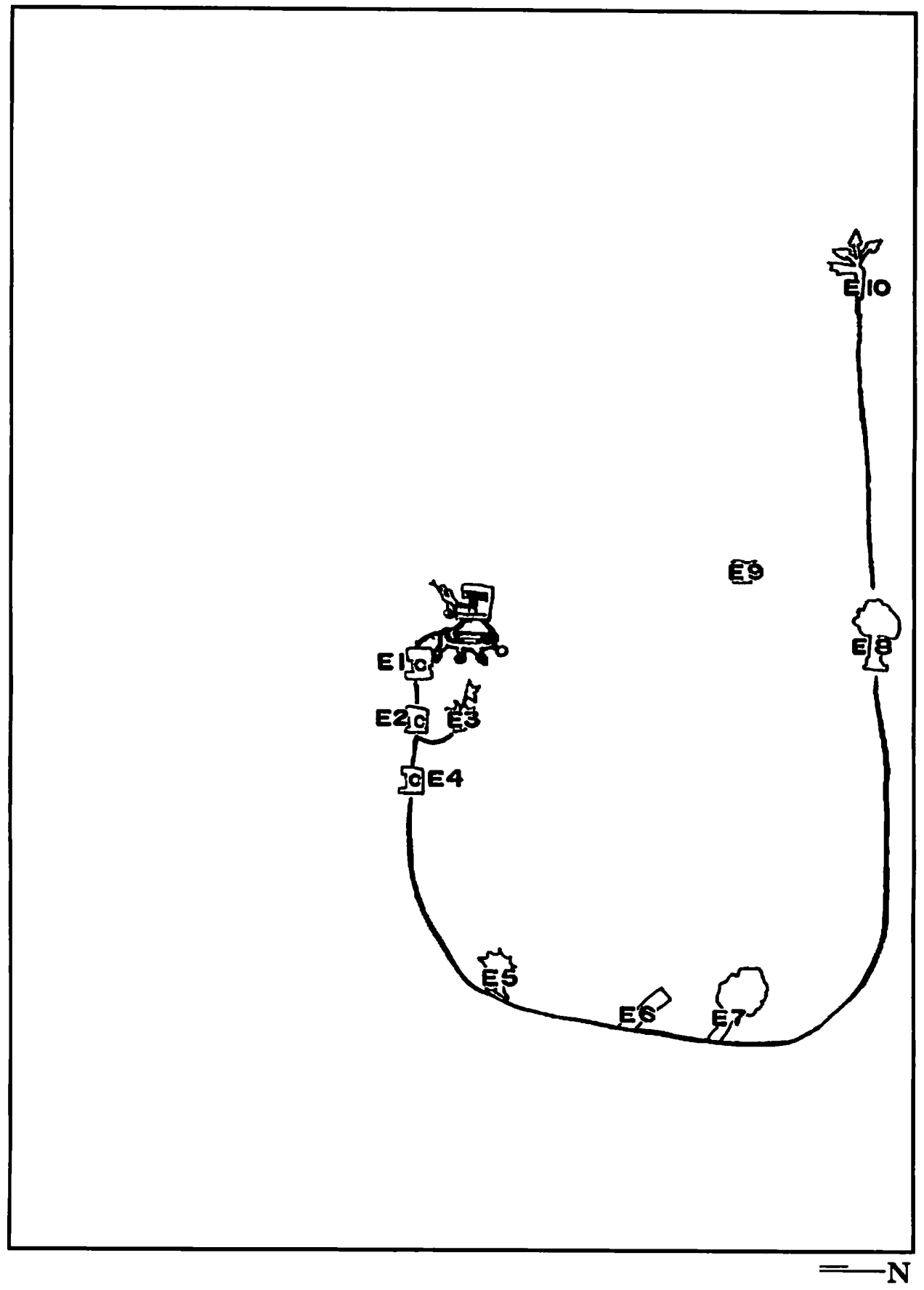


Línea F (rojo)

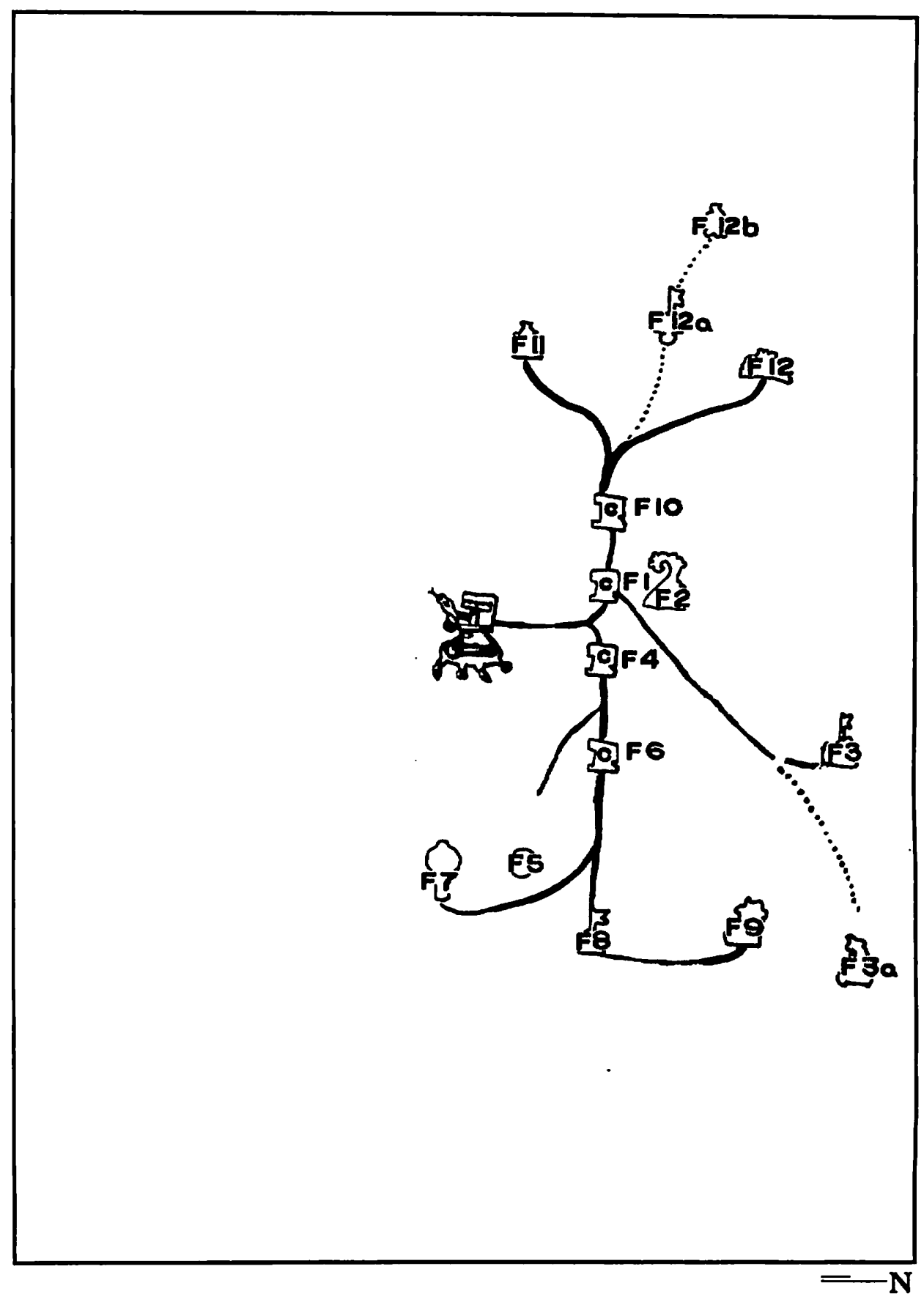


se leen como barrios para continuar con las estancias que de acuerdo con la definición ya mencionada efectivamente son los lugares más distantes en la línea de la cabecera aunque no necesariamente los más lejanos en distancia del glifo direccional.

Consideramos que cada línea de color representa una casa señorial y los sujetos dependientes de ella. Esta casa señorial estaba encabezada por un miembro de la nobleza o tlahtoque del que dependían todos los lugares enlazados por un mismo color. Es de llamar la atención cómo en la línea $\mathrm{D}$ no existe un glifo cabecera y la línea se desprende directamente del glifo de Coatlichan lo que indica que se trata de los barrios que dependían directamente del tlabtoani o máxima autoridad del señorío.

Habría que hacer notar como en el México antiguo todos los colores tenían un simbolismo y de ellos el azul turquesa se asociaban con la nobleza, que lo indica en este caso también.

Esta clasificación permitió ubicar al mapa en el contexto geográfico que representa. Con la ayuda de la franja inferior del documento que limita con el Lago de Tezcoco, la distribución de los topónimos en el espacio facilitó su ubicación en una región entre el Lago y la sierra.

El analizar con detalle cada uno de los topónimos favoreció la comprensión de la variedad de habitantes que vivieron en este señorío. Los nombres de lugar informan tanto sobre las características físicas del mismo, como puede ser la abundancia de un tipo de árbol como el ocote o el ahuehuete que puede ser una fuente de información al estudiar las características del

medio ecológico en el que este tipo de vegetación se desarrolló. También informan sobre las características de un barrio de artesanos especializados en el trabajo de la pluma (amantecas) como sería el caso de Quetzalhuacan o si se trata de un lugar en el que había un palacio para la mujeres como Ciuatecpan o un templo como Cacualcingo o también un palacio para los guerreros de más alto rango como Tlacuchcalco.

$\mathrm{La}$ información que proporcionan los glifos nos hablan también de barrios de mercaderes profesionales originales de lugares como Chalco en el caso de Chalca puchtlan. Otro tipo de topónimos de los cuales Yxtlahuacan;lugar de la llanura es un ejemplo, sitúan al sitio geográficamente. Otro caso sería Oztolitiqui que significa dentro de la cueva.

En este momento lo que nos interesa hacer notar es la composición étnica de Coatlichan que de acuerdo con los datos obtenidos en los códices chichimecas así como en los textos se hace evidente en este señorío.

Hemos encontrado doce lugares cuyos nombres identifican grupos étnicos. Estos sitios se encuentran distribuidos en todas las casas nobles que 
anota el códice, corresponden tanto a cabeceras como a barrios y estancias. Los grupos que mas se mencionan son los tilhuaques, culhuas, ayapancas, mexicas, chalcas, chimalpanecas, tepanecas, chimalhuaques y tlahuicas.

Los tlilhuaques se identifican por un topónimo que es una gota de tinta negra. La traducción del nombre se deriva de tlilhua-tintorero y can-lugar lo que nos daría el lugar de tintoreros o de los que tienen tinta negra. En el México antiguo, la tinta negra estaba asociada con los pintores de códices o tlacuilos. Lo que significaría que en estos lugares se elaboraban estas pinturas.

Los tlilhuaques fueron uno de los grupos aliados de los olmeca xicalanca quienes fueron derrotados por los toltecas de Cholula y sus aliados chichimecas. También en el códice Historia Tolteca chichimeca, el glifo de los tlilhuaques es una mancha de tinta negra.

En este Mapa se encuentran en cinco sitios. En la línea A se pintó un barrio Tlilhuacan (A5) y una estancia Tlilhuacingo (A13)

En la línea $C$ hay un barrio Tlilhuacan (C6) y una estancia Tlilhuacan (C8) y en la misma línea casi al final de la misma hay otra estancia Tlilhuacan (C10)

El segundo grupo que aparece en mayor número son los culhuas. De este grupo ya se ha mencionado su llegada a Coatlichan durante el período de gobierno de Coxcox a fines del siglo XIV. En la línea F la cabecera (F2) identifica mediante el topónimo de cerro torcido a este grupo, así como el barrio de xicolan culhuacan, cuya traducción se deriva de xicolli-faldón del traje de los guerreros, lo que significaría "en el lugar de los xicolli de los de Culhuacan".

Un tercer lugar relacionado con lo culhuas se encuentra en la línea $D$ o sea la del tlabtoani en el barrio de tleculhuacan o "lugar de los culhuas de fuego" lo que podría interpretarse como el lugar de los valientes culhuas.

De los ayapancas grupo aliado de los olmeca xicalanca, sabemos que fueron derrotados por los toltecas y chichimecas. Dos topónimos se identifican con este grupo uno de ellos Ayapango "el lugar de los ayapancas" en la línea ocre, localizado en un conjunto de topónimos de barrios (A4) y un segundo glifo en la línea verde (C11) Tepepenayapango traducido como "en el cerro de los ayapancas".

Dos lugares se derivan de los mexicas. Uno es la cabecera en la línea $\mathrm{E}$ con la clasificación (E3) Mexicapan, entendiendo por ello " el lugar de los mexicas". Cabe recordar que es bajo el gobierno de Coxcox que un grupo de mexicas llegaron tanto a Tezcoco como a Coatlichan y otros señoríos del Acolhuacan. 
Mexicatzingo es un glifo que se localiza en la misma línea bajo la clasificación (E5) cuyo nombre sería " pequeño lugar de los mexicas".

El resto de los diferentes grupos étnicos solo contaban con un solo sitio, tal sería el caso de los Chalcas en el barrio de Chalcapuchtlan " o lugar de los mercaderes chalcas" en la línea B bajo el número (B4)

Importante resultar señalar que los pochtecas eran los mercaderes profesionales que se encargaban del intercambio a larga distancia. Las fuentes escritas mencionan como solo de ciertos lugares se les permitía salir en caravanas a realizar sus transacciones, uno de estos sitios era precisamente Coatlichan.

Los chimalpanecas se localizaban en un conjunto de barrios, bajo la clasificación. (C2) Este grupo llegó a Coatlichan durante el período de Huetzin quién gobernó aproximadamente en el año 1300.

El grupo Tepaneca contaba con una estancia en la línea F, bajo la clasificación (F3). Este topónimo llama la atención por que está formado por un glifo de piedra y una bandera, esta última es muy diferente a las banderas usadas en el sistema de escritura indígena, que son rectangulares por lo que a sido uno de los elementos que suponen la manufactura del códice en la colonia.

Los Tepanecas llegaron a la Cuenca simultáneamente con los acolhuas, sin embargo es posible que se tratase de un grupo que o bien huía del Señor de Azcapotzalco o era la intención de este gobernante tener una estancia en este lugar.

Chimalhuacapan era una estancia cuyo nombre deriva de los chimalhuaques, traducido como "el lugar de los chimalhuaques o de la gentes de chimalhuacan". Puede hacer referencia a una antigua posesión de Coatlichan que se convirtió en posesión Tepaneca durante el período de Acolmiztli.

Finalmente los tlahuicas parecen haber tenido un barrio en la línea $\mathrm{A}$ en Tlaquican. Es probable que su nombre se relacione con los tlahuicas, grupo étnico que el salir de Chicomoztoc se dirigió a Cuauhnahuac.

Como se puede notar por todos los rincones de Coaltichan se distribuyeron diferentes grupos que dependían de varias cabeceras y de un mismo tlahtoque. No deja de llamar la atención el hecho de que tanto Culhuas como Mexicas tuvieran sus propias cabeceras.

El Mapa responde así a una política del Acolhuacan de recibir a los diferentes grupos que deambulaban en el territorio solicitando tierras a cambio de reconocimiento que se traducía en tributo. Fue una política que iniciada por el lider Chichimeca Xolotl continuó hasta el siglo XVI: 
A todos los recibió benignamente Xolotl, y les señalo lugares que poblasen, mas no juntos, sino separados, y en paraje que cada uno de ellos estuviese rodeado por otras poblaciones, porque eran gente belicosa, y vivía mal seguro de su fidelidad... y aunque los hizo señores de aquellas poblaciones fue siempre con la calidad de pagar cierto reconocimiento al emperador" ${ }^{28}$.

\section{NOTAS}

1 Véase Pedro Mártir de Anglería. Décadas del Nuevo Mundo. 1964.

2 El Doctor Joaquín Galarza hace notar en su libro (1990) la importancia de la conservación de estos documentos gracias a los cuales nos podemos acercar a conocer el mundo del México antiguo y de sus sistema de escritura. Véase pág.. 28.

3 Bernal Dlaz del Castillo, describe en su obra su admiración por los registros especiales en los que se almacenaban los diferentes tipos de libros. Desafortunadamente estos recintos fueron destruidos en la ciudad de Tenochtitlan con la caida de la misma.

4 Cronistas como Fray Bernardino de Sahagún, es quien describe con mayor detalle los diferentes colores usados en el México antiguo, sin embargo es necesario todavla un estudio sobre ellos, que hasta la fecha no se ha realizado. La maestra Perla Valle (1993) hizo una recopilación de tintes y colorantes tomando como fuentes los diccionarios nahuatl espaniol de Fray Alonso de Molina y de Reml Simeón.

5 Donal Robertson(1994) en su obra hace un estudio de estas escuelas. Si bien su interés como historiador del arte hace énfasis más que nada en los estilos diferentes de los códices, su obra es de gran utilidad para todo aquél que se interese por este tipo de documentación. Véase de la pág.. 68 a la 155 , de su libro.

6 Véase el Catálogo de la Colección de Códice que hizo Jhon Glass con motivo de la inauguración de Museo Nacional de Antropología e Historia, publicado en 1964.

7 Carmen Aguilera hizo un catalogo de los Códices de México, en el que clasifica a los diferentes documentos, serialando su procedencia, fechamiento, contenido y lugar donde se resguardan actualmente.

8 Véase el catalogo elaborado por J. Glass, 1975 publicado en el Handbook of Middle American Indians. Véase J. Glass, 1964, pág.. 196

9 Véase Bernal Díaz del Castillo en Galarza, op. cit. 103

10 Galarza, op. cit. 95

11 Glifo se ha definido por Galarza, como la figura o signo que en los códices se presta para significar.Por lo cual es el significado, la figura o el signo que constituye la representación pictórica. Los glifos de la escritura mesoamericana pueden ser pictográficos, ideográficos y fonéticos.

12 Glass, J. 1975; 57

13 Palerm y Wolf; 1872; pág.. 111- 127

14 Bernal Ignacio.- Tenochtitlan en una isla.-Sepsetentas, 1972; 79 - 98

15 Véase Dibble, Ch: 1980

16 Véase de Alva Ixtlilxóchitl: T. I: $\mathbf{4 2 3}$

17 Véase el trabajo de Frederic Hicks, 1982; 231 
18 Ixlilxochitl, op. cit. 380

19 Bittman, B. 1978

20 Ixclilxóchitl, op. cit.

21 La bibliografia al respecto es muy amplia, baste con mencionar las obras de Durán, 1967; Torquemada; 1969, así como los trabajos de Robert Barlow.

22 Véase Aubin, op. cit.1885

23 Gerhard, P. op. cit. 1986

24 Gibson, Ch. 1975: 35 - 39

25 Galarza, J. op. cit. 95

26 Op, cir.

27 Palerm y Wolf, op. cit. 114

28 Ixtlilxochitl, op. cit. I: 299

\section{B I B L I O G RAF I A}

AGUILERA CARMEN, Los códices de Mexico, Instituto Nacional de Antropologla e Historia, México, 1979.

AUBIN, J. Ma. Memories Sur la peinture didactique e l'escriture figurative des anciens Mexicains, Impremiere Nationale Paris, 1885.

BITTMAN, BENTE, "El mapa de Coadinchan: pictografia de Acolhuacan", Cuadernos de la Biblioteca. Serie Investigación núm. 3, BNAH, México, 1978, pp. 3-77.

CODICE CHIMALPOPOCA: Anales de Quaubtitlan y leyenda de los soles, UNAM, México, 1945.

CORTES, HERNAN, Cartas de Relación, Porrúa, 1960.

DIBBLE, CHARLES Códice Xoloth, Investigaciones Históricas, UNAM, México, 1980.

DURAN, FRAY DIEGO, Historia de las indias de Nueva España e islas de tierra firme, Porrúa, México, 1967.

GALARZA, JOAQUIN, Estudios de escritura indigena tradicional Azteca-ndhuath, Archivo General de la Nación (AGN), México, 1979.

Amath amoxtli en papeh el libro, TAVA, S.A. México, 1990.

GIBSON, CHARLES, Los aztecas bajo el dominio españoh Siglo XVI, México, 1975.

GLASS, JOHN B. Catalogo de la colección de Códices, Museo Nacional de Antropologfa e Historia, México, 1964.

GLASS, JOHN B., ROBERTSON DONALD, "A census of Native Middle American Pictorial Manuscripst", en Handbook of Middle American Indians, vol. 14, University of Texas, Austin, pp. 3-80.

IXTLILXOCHITL, FERNANDO DE ALVA, Obras Historicas, Instituto de Investigaciones Históricas, UNAM, México.

KIRCHHOFF PAUL, LINA ODENA GUEMES Y LUIS REYES GARCIA, Historia Tolteca Chichimeca, INAH/SEP y CISINAH, México, 1976.

MOHAR, B, LUZ MARIA, "El Acolhuacan y sus fuentes", manuscrito, Cuadernos de postgrado en Antropologia Social 5, México, 1990. 
El Mapa de Coatlichan.-Códices mesoamericanos vol. 2 INAH, Benemérita Universidad Autónoma de Puebla, México, 1994.

MOLINA, ALONSO DE, Vocabulario en lengua castellana y mexicana, Porrúa, México, 1970.

MOTOLINIA, FRAY TORIBIO, Memoriales o libro de las cosas de la Nueva Espania y de los naturales de ella, UNAM, México, 1971.

PALERM, A. Y WOLF, E., "Sistemas agricolas y desarrollo del área clave del imperio Texcocano", en Agricultura y civilización en Mesoamérica, Sepsetentas núm. 32, SEP, México, 1972.

POMAR JUAN BAUTISTA, "Relación de la ciudad y provincia de Texcoco", en Relaciones geogrdficas del siglo XVI: México, núm. 8, UNAM, México, 1986, pp. 23-113. ROBERTSON, DONALD, Mexican manuscript painting of the early colonial period, Yale University
Press, New Heaven, 1959 .

SAHAGÚN, FRAY BERNARDINO DE, Historia General de las cosas de la Nueva España, Porrúa, México, 1969.

TEZOZOMOC, ALVARADO, Crónica Mexicayoth, UNAM, México, 1975.

TORQUEMADA, FRAY JUAN, Monarquía Indiana, Porrúa, México, 1969.

VALLE, PERLA, Memorial de los indios de Tepetlaoztoc o Códice Kingsborough, INAH México, 1993. 